\title{
Derecho islámico
}

\section{María Antonia Masana García1}

\section{Introducción}

El término derecho musulmán se ha generalizado, aunque lo correcto sería denominarlo derecho islámico, pues la palabra musulmán ${ }^{2}$ se refiere en la religión islámica a la persona creyente. Islam se deriva de la palabra árabe salam, que significa "paz", así como "obediencia y sumisión a Dios" (Kanafani, s. f.).

Para poder entender el derecho musulmán es necesario un conocimiento previo de la civilización y la cultura musulmanas, pues el islam no solo es una religión doctrinal y ritual: es una actitud frente a la vida, una forma de actuar frente a ella, acorde con normas que permiten tener presentes a los musulmanes, que son vicarios de Dios en la tierra, para

1 Volver al alma máter significa para todos los exalumnos retornar a momentos inolvidables de una curiosidad intelectual que se transformaba en un deseo permanente de aprender, investigar y crecer con los nuevos amigos. Mi retorno a "casa" fue producto de una iniciativa de jóvenes estudiantes: acepté su invitación para brindar una charla y, luego, para escribir el presente artículo, pues me impresionó el ímpetu, la sed de conocimientos y el compromiso con nuestra universidad que me demostraron. Este artículo es para los jóvenes que, como ellos, confían y creen en el Perú.

$2<$ http://lema.rae.es/drae/?val=musulm\%C3\%A1n>. 
que prevalezca su misericordia y su bondad en un mundo en el que debe existir paz y convivencia.

El islam, el cristianismo y el judaísmo son religiones monoteístas cuyos orígenes están en Abraham: los tres principales profetas de estas religiones son descendientes de sus hijos. Del mayor de ellos, Ismael, desciende Mohammad; y de Isaac, Moisés y Jesús. Fue Abraham quien creó una colonia en el lugar en el que hoy se encuentra la ciudad de La Meca, en donde construyó la $k a^{\prime} b a$, el lugar más sagrado para los musulmanes y hacia donde se orientan para rezar.

Otro error que existe es la creencia de que todos los musulmanes son árabes: en el mundo, sólo el $18 \%$ de ellos tienen origen árabe y no todos los árabes son musulmanes, pues hay países árabes con minorías cristianas y judías. Se calcula que cerca del $20 \%$ de la población mundial es musulmana, siendo la segunda religión con mayor número de fieles. Existen musulmanes mayoritariamente en Medio Oriente, en África subsahariana (20\%), en la India (30\%), en Europa (en un número cada vez mayor), y es Indonesia en donde se concentra la mayor población musulmana del mundo, con casi 200 millones de fieles ${ }^{3}$. En América Latina, la mayoría de árabes son cristianos y no musulmanes.

La presencia musulmana en el Perú es pequeña ${ }^{4}$ y tal vez sea esa la razón por la que aquí hay desconocimiento acerca de la religión y el derecho islámicos, pero no por ello creamos que su llegada a nuestro territorio es reciente. En 1535, se encontraba en Cajamarca la "mora" 5 Beatriz de Salcedo ${ }^{6}$, esposa del veedor de la Corona española, Pedro García de Salcedo - quien presenció la muerte de Atahualpa-, a pesar de que en 1501 se había emitido en España una real cédula mediante la cual la reina Isabel La Católica prohibió que al Nuevo Mundo fuesen "moros, ni judíos, ni herejes ni reconciliados, ni personas nuevamente convertidas a nuestra Fe, salvo si fuesen esclavos negros".

$3<$ <ttp://www.islamicbulletin.org/spanish/spanish.htm\#a3>.

4 La presencia islámica en el Perú y de sus descendientes no ha sido tan estudiada como la de otros migrantes. Lo que sí es claro es su presencia y su integración.

5 En España se denominaba así a los musulmanes que invadieron la península ibérica por ocho siglos.

6 Según Antonio del Busto, fue ella quien sembró, por primera vez, trigo en el Perú. "De cierta harina mal molida de España que se pasó a estas partes para hacer hostias sacó unos granos de trigo que halló y los sembró y florecieron" (Bartet \& Kahhat, 2010). 
En los primeros años de la Conquista llegaron mujeres moras, pues pocas fueron las españolas que se animaron a venir; eran esposas de los conquistadores, o "esclavas blancas", y sus huellas se sienten hasta el día de hoy en los hogares peruanos, a través del uso de muchos alimentos y potajes. De igual manera, la presencia musulmana en el Perú se hace evidente con los balcones moriscos de Lima7, así como con las "tapadas"8. En la actualidad, las antiguas familias peruanas de origen islámico se encuentran integradas a nuestra sociedad y la mayoría de ellas son cristianas. En Lima, Arequipa y Tacna existen mezquitas, y esta última es la ciudad en la que reside el último grupo de migrantes musulmanes, procedentes de Pakistán, que llegaron atraídos por la venta de vehículos de segunda mano.

Para procurar entender el derecho musulmán se debe comenzar por conocer al Profeta, así como la historia del islam y sus fuentes. Mahoma tuvo varias revelaciones de Dios, que fueron plasmadas en el libro sagrado, el Corán, corpus que contiene sus enseñanzas, sus dichos y sus experiencias, que conducen la vida de los musulmanes y que junto a otras fuentes sirve de inspiración para la solución de los problemas de esa comunidad. El Profeta indica a sus fieles, mediante la sharia, a modo de normas, el camino correcto en el que deben mantenerse.

El derecho musulmán es un derecho religioso, con una lógica especial que deriva de la revelación, que busca el bien, la equidad y castiga el mal. El islamismo se extiende por los cinco continentes, en países diversos y con una multiplicidad de lenguas, siendo la fe un elemento común para esa comunidad, la cual comparte un estilo de vida en el que resulta común la oración y la peregrinación a La Meca, contando con un grupo de religiosos que se encargan de velar por el cumplimiento de las enseñanzas de Mahoma y de resolver los problemas de acuerdo con un régimen jurídico ordenado y que cuenta con fundamentos y valores que no son conocidos y que muchas veces no son entendidos por Occidente.

Haremos una breve aproximación hacia un mundo desconocido y a una metodología jurídica ajena a estos lares, que busca incentivar la

7 Los balcones del Sagrario al costado de la Catedral de Lima y los del Palacio Torre Tagle, sede de la Cancillería, son muestra clara de la presencia "mora" en el Perú.

8 Las "tapadas" usaron el manto hasta mediados del siglo XIX, cuando por la riqueza del guano las limeñas empezaron a imitar la moda francesa, a pesar de que en el siglo XVI el segundo arzobispo de Lima, Toribio de Mogrovejo, prohibió su uso con la excomunión. 
investigación y el conocimiento del derecho musulmán y de todo lo relacionado con esa comunidad.

\section{El profeta}

Mahoma ${ }^{9}$ es el profeta de Dios, y las fuentes para conocer acerca de él son el Corán ${ }^{10}$, las siras ${ }^{11}$ y los hadices ${ }^{12}$. Las siras más antiguas que se conocen son "La vida del profeta de Dios", escrita por Ibn Ishaq ${ }^{13}$, y la escrita por Al-Wadiqi, "Sirat Rasul Allah". No hay coincidencia entre los historiadores respecto a la fecha de nacimiento de Mahoma, pero la más aceptada es la que indica que fue el 26 de abril del año 570, en la ciudad santa de La Meca ${ }^{14}$, y murió el 8 de junio del año 632, en Medina. Perteneció a la tribu de Quraysh y al clan de los Banu Hashim, descendientes de Ishmail (Ismael), quien fue hijo de Ibrahim (Abraham). Su padre, Abdullah Al-Mutalib, murió antes de su nacimiento, y su madre, Amina,

9 Mahoma o Muhammad, cuyo nombre era Abu I-Qasim Muhammad ibn' Abd Allah. Siempre que los musulmanes dicen el nombre del profeta señalan bendiciones, como "que la paz y las bendiciones sean con él", o "Que Allah lo tenga en Su inmensa Gloria", entre otras muchas, por cuanto en el presente artículo se mencionará su nombre bendiciéndolo con el respeto que merece. Muhammad, nombre que significa "Digno de Alabanza", es el más próximo a Allah, el amado de Allah, el último mensajero, el esclavo de su Señor. Se dice que no hay ninguna descripción del profeta que pueda describir exactamente quién fue, pues era perfecto y no existen alabanzas suficientes hacia él.

10 El Corán (en árabe, “Qur'an”), es el libro sagrado del islam, que contiene las revelaciones que fueron recibidas por Mahoma a través del arcángel Gabriel. Para los musulmanes es la fuente de su religión y la última revelación de Dios y Mahoma el último profeta de la tierra.

11 Su biografía.

12 Narraciones de los dichos y acciones de Mahoma que fueron escritos y memorizados mientras él vivía y que luego de su muerte fueron recopilados y ordenados.

13 Fue modificada posteriormente por Ibn Hisham, contemporáneo de Al-Wadiki, también llamado Al-Wakidi.

14 Abraham y su hijo Ismael habrían acampado cerca de un pozo de agua, en donde construyeron un templo al que llamaron " $\mathrm{La} K a a b a^{\prime}$ y con el paso del tiempo surgió en ese lugar la ciudad de La Meca, "Makkah", la que se convirtió en una urbe, en la que se establecieron diferentes culturas y religiones. En ella se encuentra la principal mezquita, la "Kaaba" (la casa de Dios) y es hacia ella que los musulmanes se orientan para decir sus oraciones. Está cubierta por una manta negra de seda ("kisoua"), que tiene una franja dorada con versículos del Corán. 
falleció cuando él aún era un niño, razón por la cual fue acogido por su abuelo y, cuando este murió, protegido por su tío Abu Talib.

Su niñez fue modesta y no tuvo una educación formal. Se dedicó al cuidado de ovejas y cabras que su familia poseía en las colinas cercanas a La Meca. En un viaje que realizó con su tío a Siria, se encontraron con un ermitaño cristiano de nombre Bahíra, quien advirtió al tío Abu Talib que el joven sería el profeta de su pueblo. A los 25 años volvió a realizar el mismo viaje, como mercader y al servicio de la viuda Jadiya, quien, debido al éxito de las transacciones realizadas por Mahoma en Siria y por el carácter que tenía, se casó con el joven. El matrimonio duró veintiséis años, tuvieron hijos y fue ella quien lo apoyó en la dura época en la que intentó extender el islam entre los pobladores de La Meca.

Todos los años, durante el mes de Ramadán, se retiraba a una cueva en el monte Hira, cerca de La Meca, para orar y meditar ${ }^{15}$. Al cumplir 40 años, tuvo la primera revelación de Dios; escuchó una voz interna que le dijo en tres oportunidades: “¿Lee!”, a lo que respondió que no sabía hacerlo. En la última, ante la insistencia, preguntó: “¿Qué debo leer?”, y la voz le respondió: "Lee en el Nombre de tu Señor, que te ha creado. Él creó al hombre de un coágulo". Luego, la voz le diría que él era el mensajero de Allah, y, al levantar los ojos, vio el Yibril ${ }^{16}$. Fue así como se inició la revelación del Corán ${ }^{17}$, que continuó hasta su muerte, veinte años después. Durante los tres primeros años de la revelación, únicamente las personas más allegadas a él conocían lo que le sucedía y fue en ese tiempo que la voz le ordenó "salir y advertir", y fue eso lo que hizo, mostrando a los pobladores de La Meca la falsedad de los ídolos a los que adoraban.

Los clanes de la tribu de Quraysh trataron de frenar su avance porque la nueva religión, el islam, afectaba sus intereses y su estructura social, por lo que durante tres años fue confinado junto a su pueblo en un barranco y se prohibió cualquier contacto con él. Fue en esa época que murieron su esposa y su tío y se produjo el miraj ${ }^{18}$. Tiempo después,

15 Los musulmanes lo conmemoran en una noche especial del Ramadán, a la que llaman "la noche del destino" (laila al qadr).

16 El cauce por el que el Creador del Universo le transmitía la revelación. Su viaje nocturno.

17 Llamado el Qur'an.

18 Cuando Mahoma fue llevado a través de los siete cielos y se le mostró la verdadera naturaleza de su ser y el honor que significaba el recibir la Realidad Divina por parte de su Señor. 
un grupo de personas procedentes de la ciudad de Yazrib lo escucharon cuando viajaron a La Meca, y regresaron a su ciudad llevando consigo a un musulmán, razón por la cual el islam empezó a extenderse y las personas ansiosas de pertenecer a él se asentaron en Yazrib y abandonaron La Meca. En ese periodo, cuando intentaron atentar contra la vida de Mahoma, este decidió afincarse en Yazrib, ciudad que recibió el nombre de Al-Madinat al-Munawwara ${ }^{19}$, denominándose a esos acontecimientos la Hégira, con lo cual se inició la comunidad musulmana.

Ante el avance del islam, los miembros del clan de los Quraysh los atacaron en varias oportunidades y hubo batallas en las que estos ganaron y otras en las que los de Mahoma, gracias a la ayuda de ángeles, los superaron a pesar de constituir un menor número que los Quraysh. En el quinto año de la Hégira, Mahoma suscribió un convenio con dicho clan, acordando dejar la ciudad de La Meca, pero a pesar de ello el islam se fue propagando cada vez más. A Mahoma su pueblo le brindó mando, dominio y jerarquía política, militar y religiosa, lo que llevó a una guerra santa ${ }^{20}$ contra bereberes, yemeníes, zafaris y las tribus y etnias paganas de la península arábiga.

En el décimo año de la Hégira, Mahoma dio un discurso en el monte Arafat, para manifestar a su pueblo los deberes que debían cumplir y recordarles que serían llamados a responder por sus actos. Retornó a Medina ${ }^{21}$, enfermó y murió al lado de su esposa Aisha ${ }^{22}$, no sin antes dotar a su pueblo de principios religiosos, éticos y morales, y organizar el culto mientras recibía las inspiraciones divinas, por intermedio del Arcángel Gabriel ${ }^{23}$, que se encuentran en el Corán.

A la muerte del profeta, el islam ya estaba extendido por toda la península arábiga, y la yidah se encontraba orientada al Asia y el norte de África. La sucesión de Mohama no era clara y solo había coincidencia en la necesidad de mantener la unidad de la fe, así como la soberanía religiosa y política, en vista de lo cual se acordó nombrar a un califa que fuese respetado y reconocido por todos. Luego de un periodo de luchas

19 Ciudad Iluminada.

20 La "Yihad" tiene dos acepciones: la lucha interna contra el pecado para conseguir la perfección espiritual (fitra) y la guerra santa contra los infieles y paganos, para extender el islam (Maside Miranda, 2003).

21 "Al Madinah al Nabi", la Ciudad del Profeta.

22 Su esposa más amada.

23 "Jibrail". 
y desacuerdos ${ }^{24}$, en el año 652 se designó a Abu Bakr; dos años después, a Omar al Jaytab; y a Umar Ben Affan el año 644. El cuarto califa fue Alí, quien fuera primo y yerno del profeta.

Con el paso del tiempo, el islam continuó expandiéndose y empezaron a aparecer una serie de problemas complejos que no podían ser solucionados con la aplicación de las fuentes tradicionales: el Corán y la sunna.

\section{Las fuentes del islam}

El Corán fue revelado ${ }^{25}$ a Mahoma en árabe, idioma que se convirtió, por ello, en lengua sagrada. En el Corán, Allah revela que "ha dado como religión, el islam"26, y es el Corán el que contiene el origen y el desarrollo del ordenamiento jurídico musulmán, por lo que se trata de un derecho confesional, resultando, por tanto, religión y derecho la misma cosa: las partes de un todo. Los musulmanes ${ }^{27}$ se rigen por el Corán, el que es considerado un estatuto aplicable a la comunidad musulmana de todo el mundo, que tiene como preceptos obligatorios la profesión de la fe (Shahada), la oración (Salat), la peregrinación a La Meca (Hadj), el ayuno (Sawn) y la limosna (Zakat).

El Corán es una fuente inagotable de derecho, complementado con explicaciones y narraciones de la vida del profeta frente a situaciones específicas, para lo cual existen en el libro sagrado consejos y prácticas que pueden ser utilizados para enfrentar y solucionar problemas.

El contenido jurídico del Corán se encuentra ordenado en versículos, de la siguiente manera ${ }^{28}$ :

- Versículos constitucionales (10 versículos)

- Versículos referidos al "derecho civil" (70 versículos)

24 Mahoma no indicó ni dejó nada escrito acerca de su sucesión, ni en materia de derecho, razón por la que hubo varios enfrentamientos. Fueron sus allegados quienes reunieron y ordenaron los textos del Corán.

25 A la revelación del Corán a Mahoma se le denomina Tanzil, que en árabe significa "descenso o bajada", por lo que se considera que la fuente del Corán es sobrenatural.

26 Pérez-Victoria de Benavides (2001) señala que en el Corán el islam, además de religión, tiene varias acepciones, como la de "entregarse a Alá", por lo que considera que se trata de una forma de sometimiento a la voluntad divina.

27 A la comunidad islámica (umma) solo se ingresa por el credo religioso.

$28<$ http://www.bibliojuridica.org/libros/6/2792/46.pdf >. 
- Versículos relativos al derecho internacional (25 versículos)

- Versículos relativos a la economía y a las finanzas (10 versículos)

- Versículos de carácter penal (30 versículos)

- Versículos que reglamentan el procedimiento judicial (13 versículos)

Con la muerte de Mahoma, la participación de los califas en la creación de ese ordenamiento jurídico fue fundamental: como ellos no podían legislar - puesto que la ley divina ${ }^{29}$ creada por Allah es inmutable-, su función fue la de aclarar los mandatos divinos contenidos en el Corán. A partir del año 650, con el califa Othmán Ibn Affan, se empezó a escribir el contenido del Corán, hasta que cayó el califato de Damasco, y los doctores o expertos en la ley islámica30 tomaron el control del ordenamiento jurídico islámico, de modo tal que este se convirtió en un derecho inmutable.

Si bien es cierto, el Corán es la fuente primaria y primordial del derecho musulmán - como se señaló líneas arriba-, es evidente que con el paso del tiempo y la expansión del islam, las indicaciones contenidas en el libro sagrado se tornaron insuficientes para resolver la multiplicidad de problemas que se presentaban, por lo que un siglo después de la Hégira, en Irak (Kufa y Basora), Arabia (en las ciudades santas de La Meca y Medina), Yemen y Siria empezaron a aparecer escuelas jurídicas musulmanas ${ }^{31}$, las que fueron sustituidas por las escuelas clásicas, que se formaron por la presencia de una autoridad (individual) respetada y reconocida por los musulmanes. Estas fueron de dos tipos: las heréticas (que admiten solamente como válidos los dogmas coránicos) y las sunnitas (que aceptan como parte de la ley musulmana a la tradición o sunna).

A partir del siglo XIX se produjo una llamada "occidentalización" en el ordenamiento jurídico musulmán - con hechos como la separación de la Iglesia del Estado, la codificación y el constitucionalismo en el Imperio otomano-, que se vio apoyada por las buenas relaciones de las autoridades turcas con las potencias occidentales desde el siglo XVIII, y empezó a imitarse la codificación y el ordenamiento de normas existente. Esta práctica fue imitada por otros países, pero respetando la unidad del ordenamiento jurídico musulmán, que siempre mantuvo las fuentes tradicionales que consideran como única verdadera fuente la voluntad divina.

29 La sharia.

30 Los ulema.

31 Las madahib. 
Así como se formaron nuevas escuelas, se desarrollaron nuevas fuentes del derecho musulmán, lo que posibilitó una flexibilización jurídica que permitía, de manera complementaria, al Corán y a la sunna, la solución de situaciones que hasta entonces no podían ser solucionadas. Es en ese sentido que fueron aceptadas como fuentes normativas el $i_{\text {iyma }}{ }^{32}$ y el quias ${ }^{33}$, para resolver problemas nuevos que no se encontraban comprendidos ni en el Corán ni en la sunna, que es la tradición que contiene la palabra ${ }^{34}, \operatorname{los}_{\text {actos }}{ }^{35}$, así como los silencios ${ }^{36}$ de Mahoma, mientras que la iyma supone que la providencia divina hace que Dios cuide de su pueblo y por esa razón no le permite errar.

La iyma conforma una base dogmática, mientras el quias una base lógica que, mediante un proceso inductivo y ordenado por normas, permite hallar soluciones a problemas y supone la aplicación de lo convenido en casos similares si no se hallase una solución que respondiese al espíritu de la ley (analogía iuris). De manera complementaria, se cuenta con una fuente que puso las bases del desarrollo del derecho musulmán, la interpretación doctrinal, denominada también "esfuerzo activo" de los alfaquíes ${ }^{37}$. Sobre el particular, si bien se dotó de una dinámica interna al cuerpo normativo, la dependencia de la religión continuó. Mediante esa metodología se dio vida a la ciencia del Figh, una ciencia jurídica fundamentada en la revelación y que, gracias a las diversas interpretaciones que se podían dar, enriquecía el análisis y las decisiones que se adoptarían. De esa manera, empezaron a aparecer diversas escuelas, con doctrinas traducidas por los muftíes ${ }^{38}$ y dadas a conocer en sus fatwás ${ }^{39}$.

\section{El Fiqh}

La palabra Figh significa para los musulmanes "conocimiento", "comprensión" y "profundización". El término es utilizado en todos los ámbitos del saber para destacar un estudio que se realiza de la manera más exigente posible, pero su uso es generalizado para hacer referencia a la

32 Consenso de los sabios, doctores o ulemas.

33 Analogías.

34 Qawl.

35 Fil.

36 Suküt.

37 Jurisconsultos.

38 Juristas especializados.

39 Dictámenes. 
jurisprudencia musulmana, a la que denominan "la ciencia del derecho". Inicialmente, la palabra Figh únicamente se utilizaba como oposición a la palabra 'Ilm, que significa "ciencia", porque el Corán es en sí ciencia; se referían al Corán y a su interpretación, y, de igual manera, al conocimiento de las decisiones que tenían valor jurídico y que eran transmitidas por el profeta mediante la sunna y sus compañeros. De manera complementaria, con el término Figh se referían al ejercicio libre de la inteligencia cuando se trataba de asuntos precisos del derecho, haciéndose uso del juicio personal si se ignoraba o se desconocía una regla tradicional que permitiese resolver un problema. El resultado de esa forma libre de pensar y actuar es el Ray, que inicialmente se consideraba sinónimo del Fiqh.

Las opiniones de los sabios, los Arâ, se fueron registrando y se convirtieron en elementos que eran tenidos en cuenta, pasando a formar parte del $` \mathrm{Ilm}$, junto al conocimiento del Corán, a la tradición y a las opiniones de los sabios. Se utiliza como metodología el verificar todo problema, acorde con sus líneas de transmisión; de esa manera, se hace posible poder identificar, si la fuente es el Corán, la sunna o el Ray, que la solución fuese: de carácter obligatorio, si se basaba en el primero; a modo de consejo, si se basaba en la segunda; u opcional, si la base era el tercero; con lo que se hacía posible graduar las respuestas de acuerdo con tales consideraciones.

El Ilm al-figh ${ }^{40}$ pone en evidencia la división entre las fuentes primigenias y las contenidas en la sharia ${ }^{41}$. El primero de ellos abarca al derecho penal, al procesal, al tributario, a los derechos patrimoniales, a los derechos reales y a la capacidad jurídica de las personas; quedando fuera del mismo los fundamentos de la autoridad ${ }^{42}$.

\section{La sharia}

Abarca todos los aspectos de la vida de un musulmán: la vida religiosa, económica, política y social, por lo que comprende el derecho de familia, las sucesiones, la propiedad, y se aplica igualmente al derecho admi-

40 Ciencia del derecho islámico.

41 Normas que fueron reveladas por Dios y que los musulmanes las tienen como guía en la práctica de su fe.

$42<$ http://www.musulmanesandaluces.org/hemeroteca/75/nociones $\% 20$ sobre $\% 20$ el\%20figh.htm>. 
nistrativo, al penal y al de guerra. Abarca todos los asuntos legales ${ }^{43}$ de la vida de los musulmanes.

La sharia indica el camino recto por el que debe conducirse el feligrés musulmán y contiene normas de origen divino reveladas por Dios, por lo que no se trata de normas consuetudinarias. Regulan la vida de los musulmanes para que caminen en la fe y busquen una recompensa en el más allá.

A pesar de ser normas divinas, existen dos tipos de derechos: los derechos primarios (Huquq Allah), referidos a Dios y a la utilidad pública, y los derechos de los hombres (Huquq al-adamyn), referidos a la vida privada de las personas. Sobre los fieles, prevalecen los Huquq Allah, por ser divinos.

Todo creyente es sujeto de derecho; para los no creyentes, existe legislación desde el comienzo del islamismo. Dios tiene un pacto libremente acordado con sus fieles, quienes aceptan convertirse en creyentes, por lo que están obligados a cumplir sus indicaciones. En el Corán se indica con claridad la existencia del mismo, pues se señala: "Estas son las leyes de Dios, no las violéis. Quienes violen las leyes de Dios, estos son los impíos" 44 .

\section{Conclusiones}

Mahoma, luego de la revelación divina, pretendió emitir normas morales y religiosas para ordenar la vida de sus creyentes, pero no crear un sistema jurídico imperativo y coercitivo, ni convertirse en un legislador supremo. El derecho musulmán fue producto de la imperfección del hombre.

Para los musulmanes, derecho y religión son la misma cosa, están unidos intrínsecamente, son inseparables y tienen el mismo objetivo: el bienestar de los fieles. El islam es un sistema de creencias, y el derecho islámico es una legalidad de revelación divina, con una lógica jurídica diferente de la occidental.

Las fuentes sagradas son el Corán y la sunna, que contienen las palabras y el comportamiento del profeta. Se complementan con las fuentes humanas, que han permitido respuestas a situaciones que no podían ser resueltas con las fuentes originales, es decir, el consentimiento unánime de la comunidad musulmana, el razonamiento por analogía, la jurisprudencia y la ley.

43 Mualmalat.

44 II, 229 y 230 Corán. 
La lógica y la racionalidad del derecho islámico son únicas y diferentes de las occidentales, de ahí la importancia de conocerlas y entenderlas. Deben ser entendidas en un contexto islámico acorde con sus creencias y realidades.

El mundo globalizado de hoy está permanentemente comunicado; la velocidad de las informaciones se acelera cada día, sin pausa. Lo que sucede aquí puede ser conocido de manera inmediata en otras latitudes, por lo que reviste especial importancia conocer y entender a otros pueblos, otras religiones, otras culturas, otras costumbres ajenas a estas latitudes. El hecho de que la presencia musulmana en el Perú sea mínima no quiere decir que por su lejanía no se haga el esfuerzo de conocer y tratar de entenderla. Mientras no se conozca al mundo musulmán, nada se podrá decir de quienes lo conforman y tampoco nada se podrá hacer con ellos.

Frente a la diversidad musulmana de países, historia, tendencias, regímenes políticos e institucionalización política de cada uno de estos, el derecho musulmán no ha tenido un desarrollo semejante, pues la evolución ha sido diferente a pesar de contar con fuentes básicas comunes.

Independientemente de las diferencias étnicas, lingüísticas y geográficas que hay dentro de la comunidad musulmana, existe la umma, una identidad común, una lealtad y pertenencia al grupo.

\section{Referencias}

Abu-Sahlieh, S. A. (1985). La définition internationale des droits de l'homme et l'Islam. Revue Generale de Droit International Public.

Bartet, L., \& Kahhat, F. (2010). La huella árabe en el Perú. Lima: Congreso del Perú, Fondo Editorial.

Benkheira, M. H. (2008). Droit musulman. Annuaire de l'École pratique des hautes études (EPHE), Section des sciences religieuses, 115. Recuperado de http://asr.revues.org/index318.html

Borras, A., \& Mernissi, S. (1998). El islam jurídico y Europa: derecho, religión y política. Barcelona: Institut Català de la Mediterrània d' Estudis i Cooperació.

Cáceres Enríquez, J. (2008). Al-Aldalous au Pérou. Argel: Casbah.

Capeller, W., \& Kitamura, I. (2000). Une introduction aux cultures juridiques non occidentales. París: Bruylant. 
Coulson, N. J. (1998). Historia del derecho islámico. Barcelona: Bellaterra.

David, R. (1973). Les grands systems de droit contemporains. (5. ${ }^{\mathrm{a}}$ ed.). París.

De Larramendi, M. H., \& Peña Martín, S. (2008). El Corán, ayer y hoy. Perspectivas actuales sobre el islam. Córdoba: Berenice.

Dupret, B. (2011). Pertinence et perspectives de la référence anthropologique à la catégorie "droit islamique". Les Rencontres du CJB, N. ${ }^{\circ}$. Rabat.

Gacto Fernández, E., Alejandre García, J. A., \& García Marín, J. M. (1997). Manual básico de historia del derecho (Temas y antología de textos). Madrid: Laxes.

Kanafani, M. (s. f.). Diccionario Árabe-Español. Recuperado de http:// almadrasa.org/diccionarios/arabespanol.pdf

Mahoma. El Corán.

Maside Miranda, L. (2003). El terrorismo internacional y los talibán. Anuario da Facultade de Dereito da Universidade da Coruna, vol. 7.

Mehren, A.T. von. (1977). L'apport du droit comparé a la théorie et a la pratique du droit international privé. Revue internationale de droit comparé.

Pérez-Victoria de Benavides, M. M. ${ }^{a}$. (2001). El islam: historia, religión, derecho; Prelección del curso académico 2001-2002. Granada.

Tamayo, J. J. (2009). Islam. Cultura, religión y política. Madrid: Trotta. 
